\title{
THE DISTRIBUTION OF THE INSURANCE MARKET EFFECTS OF TORT LIABILITY REFORMS
}

\author{
by \\ Patricia H. Born** \\ and \\ W. Kip Viscusi***
}

July 11, 1999

Paper prepared for the Brookings Institution Conference on Microeconomics, June 19-20, 1998.

Please send all correspondence to Professor W. Kip Viscusi, Hauser 302, Harvard Law School, Cambridge, MA 02138. Phone: 617/496-0019, fax: 617/495-3010, email: kip@law.harvard.edu.

* A variety of helpful suggestions were provided by Kenneth Abraham, Dennis Carlton, Cliff Winston and Brookings conference participants.

\footnotetext{
* Assistant Professor of Finance, University of Connecticut.

** John F. Cogan, Jr. Professor of Law and Economics, Harvard Law School. Viscusi’s research was supported by the Harvard Olin Center for Law, Business, and Economics and by the Sheldon Seevak Research Fund.
} 


\begin{abstract}
This paper considers the effect of tort liability reforms on medical malpractice and general liability insurance markets. The primary reforms analyzed were damages caps and other liability reforms. These reforms decreased premiums, reduced losses, and improved the profitability of insurance companies based on evidence using detailed individual company by state data from the National Association of Insurance Commissioners. Liability reforms reduce losses by much more than they diminish premiums. Moreover, the increase in profitability is concentrated disproportionately among the least profitable firms in the industry, thus limiting the role of competition in promoting the pass-through of cost reductions during this sample period.
\end{abstract}




\section{The Impetus for Liability Reforms}

The mid-1980s marked a period of tremendous escalation in liability insurance premiums ${ }^{1}$. Particularly for medical malpractice, product liability, and environmental liability there was a dramatic surge in premium costs. Whereas some insurance lines, such as automobile insurance, were comparatively stable, premiums for general liability and medical malpractice insurance doubled in a two-year period from 1984-1986. ${ }^{2}$ Increased prices were accompanied by availability problems and insurance rationing.

Many observers suggested that this substantial rise in costs had widespread economic effects. Motels removed diving boards from their swimming pools, pharmaceutical firms stopped innovation for high-liability risk products such as those for pregnant women, and even entire industries, such as the private aircraft industry, were seriously threatened. The irony of these effects is that many critics suggested that increased liability was not even making our lives safer, as it prevented potentially health-enhancing products such as prescription drugs and other innovations from reaching the market. The rise in medical malpractice liability raised similar concerns as well. The high insurance costs led to a decrease in the proportion of doctors in some very high insurance cost specialties, such as obstetrics and anesthesiology. This trend has been linked to the rise in medical malpractice insurance costs, though such conclusions are based largely on case study evidence. Another critique is that rising medical malpractice costs gave rise to defensive medicine, whereby physicians ordered unnecessary tests or procedures that might ultimately affect liability, but would not significantly affect the actual health of the patient. ${ }^{3}$ Such effects would raise medical costs for the economy. Much of the recent debate in the 1990s over rising health care costs also focused on the potential role of medical malpractice insurance as a contributing cause to the rising cost of medical care in the U. S. economy.

This study does not focus on the causes of the liability crisis or on its economic ramifications. Rather, our emphasis is on the insurance market effects of states' response to this medical insurance crisis through a variety of tort reform measures enacted during the mid- and 
late-1980s. What was the character of these reforms and how did these efforts affect the functioning of liability insurance markets?

The occurrence of an insurance liability crisis and a reform response is not a unique event in the history of the insurance industry. There was a similar set of reform initiatives in response to the medical malpractice liability crisis of the 1970 s. $^{4}$ The wave of liability reforms in the 1980s is of interest from the standpoint of two different aspects. First, what was the overall effect of the reforms on insurance market performance? Did the reforms in fact reduce losses, premium costs, and profitability as expected? Second, did these effects differ according to different segments of the insurance market? What was the distribution of the effects across the market? Were the benefits primarily concentrated among the largest firms, the most profitable firms, or the least efficient firms?

For this inquiry we will use a very detailed micro-dataset. To assess the insurance market effects, we will use the complete ratemaking files of the National Association of Insurance Commissioners, where the unit of observation will be each insurance company writing medical malpractice or general liability coverage in each state by year. This is the largest scale database that has ever been employed in any study of the effect of general liability or medical malpractice, and it exceeds the level of detail in any study in the literature. ${ }^{5}$

The character of the analysis that we will provide for each of these classes of effects of liability reforms is in terms of identifying the nature and the extent of the consequences of the reforms. What were the reforms and did they have a significant effect on premiums, losses, loss ratios, and litigation patterns? We will not inquire into the more fundamental issue of whether these effects are desirable. Many of the consequences of the reform efforts will be to decrease medical malpractice or general liability costs. Bringing liability costs under control is clearly an important component of the social welfare calculus, especially in a period of insurance market instability that had broad ramifications for a wide variety of economic activities. These reforms reduced uncertainty not only for insurance companies but also for their customers. Assessing the 
character of the reforms and whether they in fact enhance the efficiency of the tort liability system also is a consideration regarding the overall assessment of efforts to restrain liability costs ${ }^{6}$.

The most interesting and distinctive aspect of our analysis is our inquiry into the distributional consequences of the reform efforts across the segments of the market. Which insurers benefit the most from the liability reforms? Is it the large firms, the least profitable firms, or are the effects equally distributed across all insurers? We are particularly interested in whether the reforms are conferring the greatest benefits on the least profitable firms, those that are likely doing a poor job of choosing the risks they insure. Consequently, damages caps reduce the penalties for poor underwriting practices. We use quantile regression methodology to assess the potential differential effects of the reforms across the insurer profitability and size distributions.

Considering the effects on both medical malpractice and general liability insurance offers several advantages. First, the character and timing of the reform efforts differ across the two types of insurance so that there is additional information to be gained by examining both sets of reform efforts. Second, the markets themselves differed in terms of their scale, the companies offering the coverage, and the entities purchasing insurance. Third, the reform efforts targeted firms in markets that did perform somewhat differently in the period just before the reform efforts. The percent change in liability premiums for general liability insurance was somewhat higher than for medical malpractice. Moreover, as it will be shown below, the profitability of the insurance also differed across the two lines, with general liability insurance tending to be less profitable on average.

\section{An Overview of Tort Liability Reforms}

The reform efforts enacted by the states were quite diverse. Table 1 summarizes the types of reform efforts by state and by year for reform efforts affecting damages amounts. Some 
states focused their efforts on strict caps on the magnitude of damages. Others limited the value of noneconomic damages, principally pertaining to pain and suffering and the loss experienced by survivors after the death of a family member. Unfortunately, the wide variety of restrictions in the reform efforts and the different circumstances in which the restrictions would become applicable prevents construction of a single quantitative index of the stringency of the reform effort.

Reforms designed to limit the circumstances in which damages may be awarded took a variety of forms. Idaho's reform required a plaintiff to prove "oppressive, fraudulent, wanton, malicious or outrageous conduct" in a plea for punitive damages (1987). Missouri bifurcated the trial process such that actions involving punitive damages first involve the determination of the defendant's liability for all damages sought, without regard to the amount of punitive damages. In the second part of the trial, the jury determines the amount of the punitive damages (1987). Still other reform efforts restricted punitive damages or attempted to alter the character of the liability rules applied to physician behavior. Most of the caps on compensatory (economic and noneconomic) damages for medical malpractice and general liability cases fell in the range $\$ 225,000$ (e.g., in Michigan, 1986) to \$875,000 (e.g., in New Hampshire, 1986). Punitive damages were generally capped at a lower level, ranging from $\$ 100,000$ (e.g., in Alabama, 1987) to $\$ 250,000$ (e.g., in Georgia, 1987). In two states, where compensatory damages caps were imposed specifically on medical malpractice cases, the cap was set at $\$ 1,000,000$ (e.g., in West Virginia and Wisconsin, both in 1986).

Despite the flurry of activity, there has been considerable doubt about the efficacy of the reform efforts in altering the liability landscape and in affecting the level of insurance costs. ${ }^{7}$ One potential reason for skepticism is that damages caps only pertain to the highest cost awards.

Although these tend to be the most publicized awards, the public's perception of the frequency of million dollar verdicts is far out of line with their actual prevalence. ${ }^{8}$ Indeed, there is a greater level of overpayment of small economic losses than large economic losses, for which the 
replacement rate (i.e., ratio of payment to the dollar value of economic loss) tends to be less. The award cap also may not bind juries if they adjust other components of the award to avoid the constraint imposed by a damages limit. Whether such compensating jury behavior is consequential has not been determined.

This study extends our previous work reported in Viscusi and Born (1995) in which we focus primarily on the case studies of the medical malpractice reforms in Michigan and Wisconsin, coupled with exploratory analysis of national data. ${ }^{9}$ We will consider the same types of reforms that were the focus of that paper, but our statistical analysis of the insurance consequences will be much more extensive. In addition, we examine the effects of these reforms on general liability insurance markets as well. Although both medical malpractice and general liability reforms were generally selected from a similar menu of reform efforts, the states that chose to make these reforms differed. Moreover, the type of reform picked by particular states also varied either in terms of its timing or its character. For example, Florida adopted limitations on the circumstances in which damages may be awarded for medical malpractice cases in 1985 . Florida then enacted similar restrictions for general liability in 1986 but also imposed a monetary cap on non-economic damages as well. As is indicated in the breakdowns in Table 1, many more states adopted general liability reforms over the pivotal reform era from 1985-1987 than did adopt reforms pertaining only to medical malpractice.

The reform effort breakdown in Table 1 distinguishes reforms that affected medical malpractice specifically as well as general liability reforms of a broader character. The empirical analysis will pool these reform efforts in its analysis of medical malpractice. Overall, thirteen states enacted medical malpractice reforms, with most of these reforms occurring in 1986, which was the last year of the 1984-1986 surge in medical malpractice insurance premiums. In the case of general liability reforms, 1986 was a prominent year, but 1987 featured a greater number of reforms, as sixteen states enacted reforms in that period. 
A particularly striking aspect about the reform efforts in these various periods is the strong correlation among them. The correlation within states is reflected in patterns such as the experience in Kansas. Kansas enacted two medical malpractice reforms in 1985 (a monetary cap on punitive damages and limitations on circumstances in which damages may be awarded), and followed with two more medical malpractice reforms in 1986 (a monetary cap on noneconomic damages and a monetary cap on all medical damages). These efforts were once again amended by a general liability reform in 1987 (a limitation on the circumstances in which damages may be awarded). There is also an additional correlation among the kinds of damages reforms enacted in any given period. Of the nine medical malpractice reforms enacted by states in 1986, seven of them involved a monetary cap on noneconomic damages. Similarly, of the eighteen general liability reforms enacted in 1987, twelve of these reforms imposed limitations on circumstances in which damages may be awarded. An interesting empirical question is whether these different waves of political reform activity were consequential in affecting the functioning of the liability system.

Because of the substantial correlation among various reform efforts, it is not feasible to reliably estimate the effect of each different reform effort. Our focus instead will be on two categorizations of reforms - a 0-1 categorical variable for whether a damages cap was imposed and a $0-1$ categorical variable for whether some other kind of reform was enacted. Further refinement of the categorizations did not yield stable empirical estimates. Both medical malpractice and general liability reforms are pooled for this analysis of medical malpractice insurance, whereas only the general liability reforms will be used in the general liability insurance analysis.

The 0-1 categorical variable approach to characterizing the reforms will capture the average effect of the reform efforts on the liability system. This variable will not enable one to distinguish whether a liability cap of $\$ 300,000$ will be more effective than a liability cap of $\$ 500,000$, for example. Ideally, it would be useful to be able to categorize all the various reform 
variables in some quantitative fashion to have a continuous quantitative scale for measuring the stringency of the reform. However, in addition to the monetary value of the cap, there are also many qualitative restrictions placed on the reward or accompanying the reform character of the liability rules. Because of this substantial diversity in the nature of the reform legislation components, the most feasible empirical approach is to assess whether there was a shift in the behavior after the advent of reforms.

Our focus will be solely on the 1980s reform efforts. As was indicated above, there had been earlier, and in many cases similar reform efforts undertaken in the 1970s. Potentially these reform efforts could also have influenced subsequent behavior, as indicated by Danzon (1985). Our past analysis of the 1970s reforms in Viscusi and Born (1995) indicated that there was no long-term influence of these reform efforts on the current performance of the liability system. One reason for this failure to find an effect of the earlier reforms stems from the structure of the econometric analysis. In addition to examining the effect across states, we are also concerned with the effect over time. Each equation will include in the baseline the lagged value of the dependent variable. Separate estimates in which the lagged dependent variable is not included will also appear. Thus, the focus is on whether liability reforms affect the change in insurance market performance over time. To the extent that the 1970s reforms have already exhibited their influence through the current history of insurance premiums, their effects will already be captured through the lagged dependent variable.

We proceed with our analysis on the assumption that the reforms are likely to influence insurer performance through their influence on potential and actual court case outcomes. That is, we assume that insurers in reform states operate in an environment where a more well-defined legal liability system reduces underwriting uncertainty. Hence, the reforms influence the underwriting profitability of the insurer. This assumption is potentially an issue if the causality is reversed: instead of reform efforts leading to improved performance, performance levels may lead to further reform activity. In other words, the performance of the insurers in a state may be a 
primary determinant of states' willingness or motivation to enact a reform. If our assumption is not valid, the potential bias of our results is minimal given the firm-level nature of our data and the large number of firms in each state. ${ }^{10}$

\section{Data Analysis}

\subsection{Sample Descriptions}

To undertake the analysis of the effect of the liability reforms on medical malpractice and general liability insurance markets, we utilize the complete insurance financial data files compiled by the National Association of Insurance Commissioners. These data include information on every insurance company writing medical malpractice insurance, general liability insurance, or both, by state and by year for the United States. Specific data elements include premiums earned and losses incurred, by line of business, for all insurers in the United States, reported separately for each state in which the insurer operates. It is the most complete dataset of insurance company financial information available. For the period 1984-1991, the sample contains over 8,000 observations for medical malpractice insurers and over 67,000 observations for general liability insurers. In our analyses with lagged dependent variables, our panel is limited to the period 1985-1991.

Table IIa summarizes the medical malpractice insurers sample characteristics, and Table IIb summarizes the general liability insurance company data. For simplicity, we present the sample means and standard deviations for two particular years in the data. The 1985 period is in the middle of the 1984-1986 liability crisis and coincides with the first year in which some states enacted liability reforms. The 1991 statistics reflect the performance of insurers several years after the liability reforms were implemented.

An overall shift in performance of the medical malpractice insurance industry over that period is evident from the statistics in Table IIa. Although premiums earned rose substantially over the period - by 46 percent - losses actually declined by 5 percent. The net effect is that the 
ratio of losses to premiums, the loss ratio, dropped from 1.6 to 1.0. If we ignore the interest earned on premiums before losses are paid, then 1.0 is the break-even loss ratio amount.

The experience in the general liability insurance industry was equally striking. As indicated in Table IIb, premiums earned rose 24 percent over the period while losses incurred declined by 14 percent. The net effect is that the loss ratio dropped from 1.8 to 1.3 . There clearly was a dramatic improvement in the loss performance and profitability of insurers writing medical malpractice or general liability insurance over that period.

These improvements in underwriting performance overstate the improvement in profitability, however, due to the role of interest that is earned on premiums. Because losses are paid out after premiums are paid, in periods of high interest rates, such as the early 1980's, interest rates may be sufficiently high that writing insurance can be profitable even with loss ratios below 1.0. As is indicated in both tables, the real (i.e., inflation-adjusted) Treasury bill rate dropped from 3.7 percent in 1985 to 1.8 percent in 1991. Insurance premiums were more profitable from an investment standpoint in 1985, thus making it more feasible to write insurance coverage with more unfavorable expected loss ratios. An improvement in overall performance is evident in the change in the average firm's return on equity, ${ }^{11}$ a measure that reflects the firm's performance in both the underwriting and investment activities. Average return on equity was negative in 1985, but improved substantially through this period, to an average of 0.17 in 1991 .

Table IIa provides additional information on the exposure of the malpractice insurers to liability reforms and rate regulation. The principal reform variables included in the analysis are 0-1 categorical variables for whether there was a damages cap in the state or whether the state undertook some other reform (including areas such as joint and several liability, frivolous suits, structured payments, attorney's fees, collateral source rules, and liability limits). The prevalence of each kind of reform increased dramatically over that period. In the case of damages caps, for example, only 12 percent of all medical malpractice insurers' operations were affected by damages caps in 1985, while in 1991, 65 percent of these companies wrote coverage in states 
where damages caps were applicable. The presence of other reforms more than doubled in importance over that time as well. The proportion of firms operating in states with strict rate regulation was fairly stable, rising from 27 percent to 29 percent over the period.

Measures for the rate regulation structure for the state were consistently insignificant in our exploratory regressions. Since both general liability insurance and medical malpractice insurance tend to be purchased by corporate and institutional entities rather than individuals, the states do not regulate pricing in these lines, whereas regulation is binding for consumer oriented lines such as auto insurance.

The empirical analysis will also include measures of insurance firm characteristics, i.e., whether the firm was a stock company, a mutual, a reciprocal, or Lloyd's. These organizational forms may have different incentives due to the different structure of the agency relationships that vary with organizational form. The dominant organizational structure for medical malpractice insurance is stock companies, which pertain to roughly 90 percent of the sample throughout the time period analyzed. In exploratory analyses we also examined the interactive influence of stock companies and the reform variables, but these effects were not statistically significant.

We include national premiums written in our analysis to control for the size of the overall insurance organization and capture the potential for economies of scale to be reflected in the performance of the insurer at the state level. As Table Ila indicates, average national premiums written fell from $\$ 38$ million to about $\$ 32$ million in this period.

The final set of control variables pertains to market structure and state characteristics. In particular, we will take into account the 4-firm concentration ratio as a measure of industry concentration and will also include the value of real state aggregate income. This final variable may have multiple types of influences, such as reflecting the preferences of voters in the state as well as being an index of the magnitude of the financial loss associated with the lost earnings component of a medical malpractice suit. 
Table IIb presents these same statistics for the general liability insurance sample. The prevalence of each kind of reform increased dramatically over that period for these insurers as well. In the case of damages caps, for example, only 20 percent of the general liability insurers' operations were affected by damages caps in 1985, while in 1991 over 60 percent of these companies wrote coverage in states where damages caps were applicable. The presence of other reforms increased from 68 percent to 92 percent over the period. The proportion of firms operating in states with strict rate regulation was stable at about 27 percent throughout the period.

Table IIb also indicates that stock companies are the dominant organizational structure for general liability insurers. A consistent 87 percent of all general liability insurers are organized as stock companies in the time period analyzed.

Contrary to the trend in medical malpractice, the average national premiums written of general liability insurance companies increased over the time period, from about $\$ 57$ million to \$68 million. Industry concentration, at $0.24-0.27$ over the time period, is much lower among these insurers than in the medical malpractice industry, where concentration fell slightly from 0.79 to 0.68 . Overall profitability, measured by the return on equity, improved substantially from -0.10 in 1985 to 0.132 in 1991.

Ideally, if liability reforms have their intended effect, they should decrease losses, subsequently decrease the premiums that firms are charged for coverage, and improve insurance company profitability above what it had been before the liability crisis. One might expect premiums to be perhaps less affected than losses by tort liability reforms to the extent that insurance company operations were previously unprofitable. Higher premiums would be necessary to restore companies to their pre-crisis level of profitability and to a more normal level of competitive profits. Since our analysis distinguishes effects of damages caps for states with damages reforms and those that did not have reforms, we are able to assess whether the rise in premiums was particularly great in states where no reforms were enacted, which is what one would expect on a theoretical basis. 
Although examining the effect of liability insurance on premiums, losses, and loss ratios is instructive, it is the loss ratio which is the main index of insurance market performance. The loss ratio is the inverse of ex post insurance profitability and the central measure of interest, whereas the cost and premium results show the mechanisms of interest. ${ }^{12}$

In a competitive insurance market firms will enter and exit the industry until the loss ratio for a new entrant is just sufficient to provide a normal level of profitability. If liability reforms improve profitability, competition will ensure that the industry returns to a normal level of profitability in the long run. Even in the absence of reforms, competition will lead to long run normal profits. The main differences are the timing of the return to profitability and possibly the mix of firms writing coverage. A reduction in premium rates could achieve such a pass-through. If all firms are identical, have similarly risky portfolios, and are affected in the same way by liability reforms, then firm profitability will be unaffected by the cost reductions generated by the reforms. Insurance purchasers will be the principal beneficiaries of the reform effort.

This idealized result may not hold due to a variety of characteristics of insurance markets. Suppose, for example, that firms differ in their level of profitability and that the reform benefits only the less profitable firms in the industry. In such cases, there would be no post-reform premium competition from the more profitable firms or new entrants who likewise would not benefit from the reforms. Thus, the character of the reform effort and the distribution of its consequences will have a fundamental effect on who benefits from the liability reforms.

Since we are concerned with the potential differential effect of liability reforms on firms that are less profitable, it is instructive to examine the stability of firm profitability over time. That is, we ask whether firms in the highest quantiles of the loss ratio distribution (the least profitable in terms of their underwriting performance) are consistently located in the highest quantiles, or if the relative performance of the insurers is variable. We expect stability over time, but we rely on some variability to add credence to the empirical analysis. Without variation over 
time, our quantile regression results reflect only the unique characteristics of the companies in the quantile.

Table IIIa presents a cross-tabulation of the number of observations on medical malpractice firms by their position in the loss ratio distribution for 1985 (row) and 1991 (column). For example, the table indicates that 4 firms from the highest quantile in 1985 fell to the 50-75 percent range of the distribution in 1991. The bulk of observations on the diagonal suggests general stability among the firms, but the off-diagonal cells indicate a substantial amount of variation in relative performance.

The stability of performance among general liability insurers is evident in Table IIIb, where the bulk of observations is, again, located on the diagonal or in cells adjacent to the diagonal. However, the off-diagonal cells indicate variability in relative performance among these insurers as well. There is also little evidence to suggest that firms in the highest quantiles (worst performance) are unable to recover. Interestingly, among the firms that remain in the sample for all seven years, none of the medical malpractice firms holds a position in the lowest quartile $\left(<25^{\text {th }}\right.$ percentile) for more than six years straight, and only 12 firms occupy the lowest

quartile for 3 years. Similarly, only 2 general liability insurers occupied the lowest quintile $\left(<10^{\text {th }}\right.$ percentile) for the seven years used in the analysis.

\subsection{The Effect of Liability Reforms on Insurance Company Loss Ratios}

The most prominent variable of interest in the empirical insurance literature is the loss ratio. Insurance premiums reflect the combined influence of the price of insurance and the quantity of insurance sold. Similarly, loss values will be higher if more coverage is written. The loss ratio, which is the ratio of losses incurred to premiums earned for policies written in year $t$ serves as a measure of the ex post price of insurance. This variable simultaneously recognizes the influence of price and quantity in driving premium levels and attempts to serve as a measure of insurance company profitability. The high loss ratios experiences among malpractice and general 
liability insurers in the mid-1980s, which were well above 1.0, served as a primary impetus for many of the tort liability reform efforts.

Appendix 2 presents comparable results for premiums and losses (See Section 3.3 for discussion). Total premiums earned is not the ideal measure for tracking the efforts of liability reforms since it reflects the combined influence of price and quantity. However, no price or quantity information, such as the number of policies written or extent of coverage, is available to disentangle these components.

The character of the reforms is such that they will first exert their influence by reducing the size of damage awards and their frequency. Insurance losses should reflect the first evidence of the reforms' effects. Once the effort on losses becomes apparent, insurance companies will revise their premium level, but this effect occurs with a lag after the loss effect for institutional reasons, such as their need to obtain regulatory approval of rate changes. Given this lag structure, there will be an improvement in firm profitability as reflected in lower loss ratios. Any reduction in premiums as a result of this enhanced profitability will lag behind the loss ratio reductions.

If firms were formerly at a competitive rate of profitability before the tort liability reform efforts, then we would expect any diminishing of loss levels to lead to a reduction in premiums. To the extent that the loss ratio is a valid index of insurance company profitability, ${ }^{13}$ one would expect competition to adjust so that the loss ratios would be unaffected by the reform efforts. In contrast, if loss ratios were excessive, then restraining tort liability reforms could accelerate the return to profitability of insurance companies, particularly in states in which there are limits imposed by regulatory authorities on raising premium levels.

We use a quantile regression model to assess the effects of the liability reforms on the loss ratios of medical malpractice and general liability insurers. In particular, instead of focusing on the average effects of the covariates on the loss ratio, we explore the potential differential effects across the distribution of loss ratios. Specifically, we focus on the determinants of whether the loss ratio lies within a particular quantile of the overall loss ratio distribution. Using 
the quantile regression methodology, we can obtain estimates of the influence of our covariates at any point of the distribution of the dependent variable. The most common form of quantile regression model is the median regression, which is very similar to ordinary least squares (OLS) regression, except that the method involves minimizing the sum of the absolute residuals rather than the sum of the squares of the residuals. Unlike OLS, quantile regressions do not impose normality distributional assumptions on the error term. Since we are interested in the effects of the reforms across the distribution, we supplement median regression analysis with generalized quantile regressions estimated at the $10^{\text {th }}, 25^{\text {th }}, 75^{\text {th }}$, and $90^{\text {th }}$ percentiles. To control for possible heteroscedastic errors, we use a bootstrap resampling technique to obtain standard errors. The quantile regression methodology is discussed in more detail in Appendix 1.

Tables IVa-IVh report the quantile regression results in which we assess the effects of the liability reforms on loss ratios. For each of the two samples of insurers, we estimate these effects following two functional forms, beginning with a standard autoregressive formulation in which we include the lagged dependent variable in the vector $x$. That is:

$x=f\left(\right.$ loss ratio $\mathrm{t}_{\mathrm{t}-1}, 0-1$ indicators for damages reform and other reform, $0-1$ indicators for organizational form, national premiums written, four-firm industry concentration ratio, 0-1 indicator for restrictive rate filing regulation, real state aggregate income, U.S. Treasury Bill rate).

We also estimate a counterpart to this equation including a variable to capture the effect of the 1986 tax reforms. That is:

$x=f\left(\right.$ loss ratio $\mathrm{t}_{\mathrm{t}-1}, 0-1$ indicators for damages reform and other reform, $0-1$ indicators for organizational form, national premiums written, tax reform ' $86 *$ return on equity, four-firm industry concentration ratio, 0-1 indicator for restrictive rate filing regulation, real state aggregate income, U.S. Treasury Bill rate). 
Since these reforms will have the greatest benefit for the more profitable firms, the variable used is the interaction between the 1986 (and thereafter) dummy variable and the return on equity, which we measure by the underwriting and investment gains divided by total equity. Unfortunately, the timing of the tax reforms coincides with the middle of the reform period from 1985 to 1987 , making it very difficult to disentangle the two types of policy influences. In the subsequent results, the damages cap reform variable will be consistently influential for both medical malpractice and general liability, but the other reform variable will be more unstable in the general liability regression results.

We then proceed with the estimation of these two equations without the lagged dependent variable, which allows us to assess the long run effects of the reforms. Each of the tables report five sets of quantile regression results for different fractiles of the loss ratio distribution. Thus, it is possible to ascertain the differential effect of liability reforms on the less profitable firms, at the upper end of the loss ratio spectrum, as opposed to firms at the low end. The estimated coefficients indicate the influence of the covariate at that particular point of the distribution. Thus, by looking across the estimated quantiles, we can infer whether the influence of a covariate gets greater, or smaller, or is unvarying across the distribution.

\subsubsection{Medical Malpractice Loss Ratios}

Tables IVa-IVd pertain to the medical malpractice sample. In Table IVa, the importance of examining the effects of the liability reforms on different segments of the distribution is evident when one compares the estimates obtained at each of the quantiles. The results indicate that most segments of the profitability distribution are significantly affected by the reforms. Most striking is that the effect of the damages cap variable rises steadily in terms of its coefficient size as one moves from the lower quantiles to the higher loss ratio values, where these effects are statistically significant in all cases. The other reform variable likewise is most consequential at the upper end of the loss ratio spectrum. Beginning at the median loss ratio through a remarkably 
high influence at the $90^{\text {th }}$ percentile, the other reform variable decreases the value of the loss ratio substantially. The combined effect of these reform variables based on the point estimates is -0.25 at the $75^{\text {th }}$ percentile and -0.41 at the $90^{\text {th }}$ percentile. Given the mean loss ratio values of 1.60 in 1985 and 1.0 in 1991 for the sample characteristics in Table IIa, it is apparent that effects of this magnitude represent a substantial influence on the profitability of insurance company operations.

It is somewhat striking that the net influence of the lagged value of the loss ratio increases to a striking degree as one moves to the least profitable firms. For firms at the low end of the loss ratio distribution, the last period loss ratio has very little influence on current loss ratio levels. Firms at the $75^{\text {th }}$ percentile and the $90^{\text {th }}$ percentile, however, exhibit a very strong relationship across time, which is suggestive of a consistently risky and unprofitable portfolio of insurance policies written.

Table IVb reports very similar results when we include our control for the Tax Reform Act of 1986. The effects of the two reform variables are virtually unchanged, and although the new variable is only significant at the median and $75^{\text {th }}$ percentiles, it has the expected negative effect on loss ratios.

Tables IVc and IVd explore the robustness of these results with regression estimates of the model without the lagged dependent variable. Apart from a substantial decrease in explanatory power, the results are similar to those in Tables IVa and IVb. In both models, damages reforms have a consistent significant effect in reducing loss ratios, with effects at the $90^{\text {th }}$ percentile being over three times as great as for the median firm. It is the most unprofitable firms that benefit most from the damages reforms. The magnitude of the damages reform effect is slightly larger for firms above the median when the lagged dependent variable is omitted, indicating a larger long run influence on loss ratios for the more unprofitable firms. The other reforms variable performs in a same manner, with the point estimates following the same general pattern in the upper quantiles. 


\subsubsection{General Liability Loss Ratios}

The experience among general liability insurers is reported in Tables IVe-IVh. Here again, the quantile regression results indicate that most segments of the profitability distribution are significantly affected by the damages reforms. This effect also increases in magnitude as one moves from the lower quantiles (about -0.01 at the $10^{\text {th }}$ percentile) to the higher loss ratio values ( -0.2 to -0.3 at the $90^{\text {th }}$ percentile, depending on the specification). Given the mean loss ratio values of 1.8 in 1985 and 1.3 in 1991 for the sample characteristics in Table IIb, the results suggest damages reforms had a substantial influence on the profitability of insurance company operations. The other reform variable is found to be generally insignificant except at the upper quantiles, where it has a surprising positive effect, which may reflect the fact that not all liability reforms are cost reducing. 
As shown in Tables IVe and IVf, the lagged value of the loss ratio exhibits a much less striking pattern of influence among general liability insurers than among the medical malpractice insurers. The coefficients are all statistically significant, but are considerably less significant in magnitude. Again, this result is suggestive of consistently risky and unprofitable underwriting portfolios.

Tables IVg and IVh explore the robustness of the results in Tables IVe and IVf with regression estimates of the model without the lagged dependent variable. Damages reforms remain a consistently significant determinant of loss ratios and the influence is greatest among the

firms with the highest loss ratios. The estimated effect at the $90^{\text {th }}$ percentile is six times as great as for the median firm. Unlike the results obtained for the medical malpractice insurers, the magnitude of the effects of the damages reform do not increase relative to those obtained for the model that includes the lagged dependent variable. This result suggests that the damages reforms have led to permanent long run reductions in loss ratios. The other reforms variable performs less consistently, and, once again, exhibits a positive influence at the upper quantiles.

\subsection{The Effect of Liability Reforms on Insurance Company Premiums and Losses}

We also estimated the effects of the liability reform efforts on insurance company premiums and losses, the two components of the loss ratio. Because the most frequently cited index of the liability crisis is the surge in insurance premiums that took place in the mid-1980s, we were interested in the influence of the reform efforts on the level of insurer premiums. As before, we estimated the effects of the liability reforms following two functional forms: the autoregressive formulation that includes the lagged dependent variable in the vector $x$, and the same model without the lagged dependent variable. In these analyses of the effects of the liability reforms on premiums, the quantile regression results allow us to examine any differential effect of the reforms on smaller firms, at the lower end of the premium distribution, as opposed to firms writing a high volume of premiums. A summary of our results are presented in Appendix 2. 
Among medical malpractice insurers, we find that the damages reform variable is most influential, and again, has a differential effect across the distribution of firm premiums. The effect rises steadily in magnitude from a 4 percent reduction in total premiums for firms at the $25^{\text {th }}$ percentile to a high value of 13 percent at the $90^{\text {th }}$ percentile. At the $90^{\text {th }}$ percentile, this represents a reduction of over $\$ 2,000,000$ in premiums for these firms. The effect of the other reform tort liability variable is not statistically significant. Interestingly, when we omit the lagged dependent variable, the damages reform variable is less significant and no longer follows the pattern exhibited in the first equation. Also, the other reform variable exerts a positive effect across the distribution.

For general liability insurers, damages reforms have a fairly uniform negative effect on premiums, ranging from about $5.8-8.4$ percent. The estimated effects of the other reform variable are insignificant at the lower quantiles, and positive and significant at the $75^{\text {th }}$ and $90^{\text {th }}$ percentiles. When the lagged dependent variable is omitted from the model, damages reform is no longer a consistent determinant of premiums across the distribution, but the other reform estimates indicate a positive, and generally uniform, relationship between reform and total premiums. The results suggest little correlation between the size of the general liability insurer and the effects of the liability reforms.

The analysis of insurer premiums suggests that when the pertinent aspects of other factors that drive premium amounts are controlled, the damages reforms had some success in controlling premium levels. Although the initial intent of the reforms is to affect loss amounts, the ultimate economic mechanism at work should involve a passthrough of the decreased loss levels on to insurance customers in terms of lower premium values. There does appear to be such a passthrough effect as the damages reforms did substantially reduce medical malpractice and general liability insurance premiums, but the effects of the other reforms, and the longer term effects of the damages reforms are less clear. 
Our analysis of loss ratios suggests that the liability reforms would have had a negative effect on loss levels for a given level of premiums. However, we note above that the damages reforms had a significant effect on premiums as well. Next, we explicitly tested the effects of the reforms on loss levels using the same basic model, but including contemporaneous premiums as an independent variable. These results, when compared to those obtained for the premium equations, allow us to tell a more complete story about how the reform efforts are influencing overall performance.

Among medical malpractice insurers, the two liability reform variables each indicate that the reforms were successful in restraining the level of losses. The effect of these reforms on different segments of the loss distribution is fairly consistent throughout the loss distribution in percentage terms in the case of the damages cap variable. For that reform measure, the effect on losses ranges from 17 percent to 24 percent and is consistently significant throughout all loss levels. As in the case of premiums, the greatest effect of the reforms is at the upper end of the distribution. Given a value of $\$ 4.7$ million at the $90^{\text {th }}$ percentile, the effect at this point of the distribution represents a reduction in losses of nearly $\$ 900,000$ for these firms.

When we omit the lagged dependent variable from the model, we find that the estimated effects of the liability reform variables are virtually unaffected, suggesting that the liability reforms have led to consistent long-term reductions in the level of losses. The uniformity of the effect across the loss distribution is consistent with our earlier findings with regard to premiums: there is little correlation between the size of the firm and the effects of the liability reforms.

The effect of the liability reforms on loss levels is equally striking when we examine their influence among general liability insurers. The two liability reform variables each indicate that the reforms were successful in restraining the level of losses. Also, the magnitude of this reduction is fairly consistent throughout the loss distribution in percentage terms in the case of the damages cap variable, falling slightly from 11 percent to 6 percent as you move to the upper quantiles. 
When the lagged dependent variable is omitted from the model, the estimates on the damages reform variable remain negative and significant across the distribution, and are roughly the same magnitude at all quantiles. The damages reform is largest in magnitude at the $10^{\text {th }}$ percentile, at -0.113 , and falls to around -0.06 at the median. The other reform variable exhibits a significant positive effect on losses that rises as you move to the upper quantiles.

\subsection{Additional Considerations}

In the preceding analysis we raised a few concerns that limit the quality of our results. Thus, we undertook a number of steps to evaluate the robustness of the estimates we have obtained, steps that address particular concerns with the theoretical and empirical approach. First we consider the possibility of omitted firm characteristics which may bias our results. Then, we consider the possible endogeneity of the reform efforts in our analysis of loss ratios. Finally, we note that our quantile regression approaches, viewed in unison, tell a reasonable story about the effects of the liability reforms.

Our quantile regression estimates of the effects of the liability reforms on premiums, losses, and loss ratios reveal several instances in which the effects are not uniform across the distribution. We can be fairly certain that these effects are not being driven by any particular firms in each quantile because there has been substantial variability in performance over this period, as evident in Tables IIIa and IIIb. Still, it is possible that our effects are being driven by other firm characteristics that we have overlooked, including firms' persistence in operating in particular types of markets or holding particular types of underwriting portfolios.

To assess the possibility that our reform variables are not simply capturing these other characteristics, we incorporated individual firm fixed effects variables into a variant of our $\operatorname{model}^{14}$. Our results are consistent with those obtained in the quantile regression analysis, so we can reasonably assume that individual firm effects are not important. The results of our analysis are presented in Appendix 3. 
We assumed in our analysis that the liability reforms were exogenous in the loss ratio equation. This assumption is quite reasonable given the number of firms and level of concentration in each state: it is not likely that any one firm's experience is the motivation for a state's reform efforts. Still, it is possible that states with the poorest insurance experience, on average, would be more likely to enact reforms than states with good experience. To explore the possible endogeneity of the reform and firm performance, we estimated several simultaneous equation models and performed Hausman specification tests, all of which suggested that one insurer's performance does not make a significant incremental contribution to the enactment of tort reform. If there is any endogeneity, it will tend to reduce the effect of the liability reforms. Enactment of reforms will reduce loss ratios. This improved profitability will decrease the impetus for additional liability reforms if there is such as simultaneous relationship.

Having identified large and significant effects of the liability reforms on the loss ratios, we are particularly interested in the mechanisms behind this result: namely, the relative magnitudes of the estimated liability reform effects on losses versus premiums. In comparing the findings from our analyses of premiums and losses, we find that the damages reforms reduce losses by about twice as much as the percentage effect on premiums. This result is consistent with the findings reported in the loss ratio tables -- that the liability reforms enhance insurer profitability. Where significant, the effects of the reforms on the losses and premiums of the general liability insurers suggest the same pattern. However, we found that the effect of the damages reform is much less uniform across the distribution of losses for the general liability insurers than for the medical malpractice insurers. Insurers with smaller loss levels are found to have been more affected by the reforms than those with larger losses. If the correlation between losses and premiums were stronger, we would have expected a corresponding strong negative effect on the lower portion of the loss ratio distribution, since we found no strong differential effects across the premium distribution. As we did not, we suspect that a firm's relative position in the premium distribution is not strongly related to their position in the loss distribution. 


\section{Economic Implications of the Liability Reforms}

The states enacted the tort liability reform efforts in response to the liability insurance crisis in the early to mid-1980s. The objective of this paper was to obtain an assessment of whether these efforts were successful in promoting their intended objective. To do this we analyzed detailed data on an individual basis for every company in every state writing medical malpractice or general liability insurance coverage.

The underlying impetus for these various reform efforts was the surge in losses and premiums that occurred in the 1980 s, which were coupled by a decrease in insurer profitability. These adverse insurance market effects were largely concentrated among insurance lines such as general liability and medical malpractice rather than lines such as automobile insurance. These changes led to various designations such as fears that we were undergoing a "liability crisis." These assessments of a problem rather than simply change were based largely on the magnitudes of the changes from the pre-existing status quo and the decrease in firms' profitability. Change, however, is not necessarily bad. If, for example, the previously existing level of liability was too low, then additional liability burdens would be warranted. However, there was a general sense, supported in large part by anecdotal evidence, that the rise in liability was in fact having adverse consequences, such as the depression of innovation and withdrawal of vital products and services from the market.

As a result of this surge in liability, the states sought to restrain the insurance costs imposed on firms and physicians. Over the 1984-1987 period, thirteen states adopted damages reforms pertaining to medical malpractice and 28 states adopted damages reforms pertaining to general liability. The focus of the empirical inquiry was on whether these reforms improved profitability and restrained losses and premiums. Thus, we took as the valid objective of these reforms the intent to reduce the overall liability burden and to bolster the profitability of the insurance firms, which at the time of the crisis was at a highly unprofitable level. 
To carry out our analysis we assembled what is by far the largest dataset that has yet been used to assess the effect of the liability reforms. Over the 1984-1991 period, we have information by state and by firm for every company writing medical malpractice coverage and every company writing general liability coverage, leading to over 1,000 observations per year for medical malpractice and over 8,000 observations per year for general liability. Analyzing the effect of the liability reforms on both lines of insurance is instructive since these two lines were at the center of the liability crisis. Moreover, the efforts of state legislatures sought to restrain each of these types of liability costs. These markets, however, are not identical, and the reforms also differed in their timing and their character so that there is additional variation in these efforts and in their performance that provides a fuller empirical framework for assessing the potential effects of liability reform efforts.

Despite the wide variety of statistical explorations undertaken, the result is a remarkably uniform picture of the effect of the reform efforts. Damages caps and the other reforms serve to control insurance company costs, which in turn led to a decrease in the value of premiums. There was also an enhancement in the profitability of writing medical malpractice and general liability insurance as a direct result of the medical malpractice reform measures. Viewed in the narrow terms of attempting to restrain liability costs, the reform efforts certainly are a success.

The most interesting aspect of these effects is the different distributional consequences of the reform efforts across the segments of the market. Who benefits from the liability reforms? Is it the large firms, the least profitable firms, or are the effects equally distributed? Our empirical results indicated substantial variation in the consequences of liability reform effects.

The greatest differences in terms of the distribution of the consequences were observed for the loss ratio effects. Firms with relatively high loss ratios experienced the greatest effect of the damages reforms. Thus, it is the least profitable firms in the market that reap the greatest benefits from liability reforms. These reforms serve to bolster their profitability and are not passed through in their entirety to the insurance purchasers. Since the least profitable firms have 
achieved this dubious status by writing insurance coverage for which the losses are far in excess of the premiums, there is the potential that these reform efforts may be conferring the greatest benefits on the firms that are least able to carefully choose the risks they insure. Consequently, damages caps reduce the penalties for poor underwriting practices. It should be noted that although there is considerable variation in a profitability of firms over time, many firms tend to remain in the same relative profitability position from year to year, which would reflect a persistence in the underwriting practices and portfolio mix of these companies.

The distribution of the reform variable effects for premiums and losses was less pronounced. Unlike the results for the loss ratios, there is no evident increase in the consequences of the liability reforms as one moved across the distribution of losses and premiums. These results indicate that it is not simply the large firms in the market that are benefiting from the liability reforms. Indeed, there is no systematic size-related difference in the findings. Rather, the benefits of the liability reforms are concentrated among the firms that would have suffered the greatest decrease in profitability as a result of large damages awards that would have been made had it not been for the restraining effect of the liability reform measures.

It is also noteworthy that the character of the reforms did not follow the usual textbook case in which there is a pass-through of savings to insurance purchasers, with no improvement in profitability. Although all groups of firms benefit to some extent, firms with the least profitable insurance portfolios reap the overwhelming share of the cost savings. This result may be due to the character of damages reforms. 


\section{References}

Abraham Kenneth, 1987. "Making Sense of the Liability Crisis." Ohio State Law Journal, 48: $399-411$.

American Law Institute, 1991. Enterprise Responsibility for Personal Injury-Reporter's Study Volume I and II Philadelphia: American Law Institute.

Barker, Drucilla K., 1992. “The Effects of Tort Reform on Medical Malpractice Insurance Markets: An Empirical Analysis." Journal of Health Politics, Policy and Law 17: : 143-161.

Chamberlain, Gary, 1991. "Quantile Regression, Censoring, and the Structure of Wages" discussion paper, Harvard Institute of Economic Research.

Danzon, Patricia M.1985. Medical Malpractice. Cambridge, Mass: Harvard University Press.

Danzon, Patricia M. and Lee Lillard, 1983. "Settlement Out-of-Court: The Disposition of Medical Malpractice Claims.” Journal of Legal Studies 12: 345-377.

Dewees, Don, David Duff, and Michael Trebilcock, 1996. Exploring the Domain of Accident Law: Taking the Facts Seriously. New York, NY: Oxford University Press.

Huber, Peter, 1988.. Liability: The Legal Revolution and Its Consequences. New York, NY: Basic Books. 
Huber, Peter, and Robert E. Litan, eds., 1991. The Liability Maze: The Impact of Liability Law on Safety and Innovation. Washington, DC: Brookings Institution.

Hughes, James W. and Edward A. Snyder, 1989. "Evaluating Medical Malpractice Reforms.” Contemporary Policy Issues 7: 83-98.

Insurance Information Institute, 1978. The Fact Book: 1992 Property/Casualty Insurance Facts. 1992.

Koenker, Roger and Gilbert Bassett, Jr.,1978. “Regression Quantiles,” Econometrica 46: 33-50. Koenker, Roger and Gilbert Bassett, Jr., 1982. "Robust Tests for Heteroscedasticity Based on Regression Quantiles.” Econometrica 50: 43-61.

Litan, Robert, and Clifford Winston, eds., 1988. Liability: Perspectives and Policy. Washington: Brookings Institution.

Pauly, Mark V. and Raynard S. Kington, 1990. "The Effects of Medical Malpractice Litigation on Physicians' Fees and Incomes.” American Economic Review 80: 122-127.

Priest, George, 1987. “The Current Insurance Crisis and Modern Tort Law.” Yale Law Journal, 96: $1521-1590$.

Priest, George and Benjamin Klein, 1984. "The Selection of Disputes for Litigation.” Journal of Legal Studies 13, (No. 1): 1-55. 
Schuck, Peter, ed. 1991. Tort Law and the Public Interest: Competition, Innovation, and Consumer Welfare. New York: W. W. Norton.

Schwartz, Alan, 1988. "Proposals for Liability Reform: A Theoretical Synthesis.” Yale Law Journal 97: $357-419$.

Viscusi, W. Kip, 1990. “The Performance of Liability Insurance in States with Different Products Liability Statutes.” Journal of Legal Studies XIX, (No. 3): 809-836.

Viscusi, W. Kip, and Michael J. Moore, 1993. "Product Liability, Research and Development, and Innovation.” Journal of Political Economy 101, (No. 1): 161-184.

Viscusi, W. Kip, 1991. Reforming Products Liability. Cambridge, Mass: Harvard University Press.

Viscusi, W. Kip and Patricia Born, 1995. "Medical Malpractice Insurance in the Wake of Liability Reform.” Journal of Legal Studies. XXIV: 463-490.

Viscusi, W. Kip, Richard Zeckhauser, Patricia Born, and Glenn Blackmon, 1993. "The Effect of 1980s Tort Reform Legislation on General Liability and Medical Malpractice Insurance.” Journal of Risk and Uncertainty 6: 165-186.

Weiler, Paul C., et al., 1993. A Measure of Malpractice: Medical Injury, Malpractice Litigation and Patient Compensation. Cambridge, Mass: Harvard University Press. 
Weiler, Paul C., 1991. Medical Malpractice on Trial. Cambridge, Mass: Harvard University Press.

Zuckerman, Steven, Randall Bovbjerg and Frank Sloan, 1990. "Effects of Tort Reforms and Other Factors on Medical Malpractice Insurance Premiums.” Inquiry 27:167-182. 
${ }^{1}$ For discussion of the liability crisis, see Abraham (1987), the American Law Institute (1991), Dewees, Duff, and Trebilcock (1996), Huber (1998), Huber and Litan (1991), Litan and Winston (1988), Priest (1987), Schuck (1991), Schwartz (1988), Viscusi (1991), Weiler (1991), and Weiler et al. (1993)

\footnotetext{
${ }^{2}$ These data are drawn from the Insurance Information Institute, The Fact Book: 1992

Property/Casualty Insurance Facts, 1992, pages 28-29.
}

${ }^{3}$ See Pauly and Kington (1990), Weiler (1991), and Weiler et al. (1993).

${ }^{4}$ The study by Patricia M. Danzon, Medical Malpractice (Cambridge: Harvard University Press, 1985), addressed this set of reform issues. A more recent discussion of medical malpractice reform more generally appears in Paul C. Weiler, et al., A Measure of Malpractice: Medical Injury, Malpractice Litigation, and Patient Compensation (Cambridge: Harvard University Press, 1993). For product liability, see W. Kip Viscusi, Reforming Products Liability (Cambridge: Harvard University Press, 1991).

${ }^{5}$ The principal predecessors of this study are Barker (1992), Danzon (1985), Hughes and Snyder (1989), Viscusi (1990), Viscusi and Moore (1993), Viscusi and Born (1995), Viscusi, Zeckhauser, Bovbjerg, and Blackmon (1993), and Zuckerman, Borber and Sloan (1990).

${ }^{6}$ Numerous studies have discussed the rationale for different kinds of reform and the strengths and limitations of different reform proposals. See the American Law Institute, Enterprise Responsibility for Personal Injury-Reporter's Study, Volume I and II (Philadelphia: American Law Institute, 1991).

${ }^{7}$ For example, in 1993, the Chairman of the American Bar Association's Working Group on Health Care Reform expressed his skepticism by claiming that "caps on non-economic damages have not had 
${ }^{1}$ For discussion of the liability crisis, see Abraham (1987), the American Law Institute (1991), Dewees, Duff, and Trebilcock (1996), Huber (1998), Huber and Litan (1991), Litan and Winston (1988), Priest (1987), Schuck (1991), Schwartz (1988), Viscusi (1991), Weiler (1991), and Weiler et al. (1993)

${ }^{2}$ These data are drawn from the Insurance Information Institute, The Fact Book: 1992 Property/Casualty Insurance Facts, 1992, pages 28-29.

${ }^{3}$ See Pauly and Kington (1990), Weiler (1991), and Weiler et al. (1993).

${ }^{4}$ The study by Patricia M. Danzon, Medical Malpractice (Cambridge: Harvard University Press, 1985), addressed this set of reform issues. A more recent discussion of medical malpractice reform more generally appears in Paul C. Weiler, et al., A Measure of Malpractice: Medical Injury, Malpractice Litigation, and Patient Compensation (Cambridge: Harvard University Press, 1993). For product liability, see W. Kip Viscusi, Reforming Products Liability (Cambridge: Harvard University Press, 1991).

${ }^{5}$ The principal predecessors of this study are Barker (1992), Danzon (1985), Hughes and Snyder (1989), Viscusi (1990), Viscusi and Moore (1993), Viscusi and Born (1995), Viscusi, Zeckhauser, Bovbjerg, and Blackmon (1993), and Zuckerman, Borber and Sloan (1990).

${ }^{6}$ Numerous studies have discussed the rationale for different kinds of reform and the strengths and limitations of different reform proposals. See the American Law Institute, Enterprise Responsibility for Personal Injury-Reporter's Study, Volume I and II (Philadelphia: American Law Institute, 1991).

${ }^{7}$ For example, in 1993, the Chairman of the American Bar Association's Working Group on Health Care Reform expressed his skepticism by claiming that "caps on non-economic damages have not had 
the dramatic impact that supporters think." See the statement of Clifford D. Stromberg, Chairman of the American Bar Association's Working Group on Health Care Reform, Associated Press release, August 9, 1993.

${ }^{8}$ See W. Kip Viscusi, Reforming Products Liability (Cambridge: Harvard University Press, 1991).

${ }^{9}$ See W. Kip Viscusi and Patricia Born, "Medical Malpractice Insurance in the Wake of Liability Reform,” Journal of Legal Studies, Vol. XXIV, June 1995, pp. 463-490.

${ }^{10}$ Past individual firm profitability (i.e. the loss ratio) was not found to be a significant determinant of state reform efforts. We also investigated the relationship between state reform efforts and several other measures of past performance in the state, including the average loss ratio and the upper quantiles (75th and 90th percentiles) of the state loss ratio distribution, but did not find any consistent significant relationships.

${ }^{11}$ The return on equity is defined as the sum of total investment and underwriting gains divided by the firm's total equity. This measure is calculated from a firm-level data set that contains income statement and balance sheet information for all firms in our sample.

${ }^{12}$ One potential problem with the loss ratio measure is that it is derived using losses incurred, which, to some extent, is an estimated value. During this period, it is possible that insurer's estimates of losses were not accurate, but we have no reason to believe the inaccuracies would differ across states with and without reforms.

${ }^{13}$ It excludes, for example, the role of administrative costs and variations in the rate of return earned on premium investments.

${ }^{14}$ For several reasons, we had to adjust the equations we estimated previously. Most importantly, we had to omit any variables that were specific to the firm for the entire time period, which required us to drop the organizational form variables. In addition, the estimates would be biased if we included the lagged dependent variable among the regressors, so it is omitted. Although outliers in the loss ratio distribution were not a problem in the quantile regression, we chose to estimate the effects of the reforms in a 
logarithmic form. Finally, with other 1,500 firms in the general liability sample, we encountered a limitation in our statistical software package: a maximum of 800 variables is allowed in any estimation procedure. We decided to take a random sample of one-half of the companies (769 to be exact), which consequently lowers the number of observations to just over 30,000 for this sample 